\title{
Perencanaan Pengelolaan Sampah Pasar Pelita SK 17 Desa Bangun Karya Kecamatan Rantau Rasau Kabupaten Tanjung Jabung Timur
}

\author{
Jonyyus Adi Putra*, G.M. Saragih, Marhadi, \\ Program Studi Teknik Lingkungan Universitas Batanghari \\ *e-mail : jonyyus@gmail.com
}

\begin{abstract}
ABSTRAK
Pengelolaan adalah kegiatan sistematis, menyeluruh dan berkesinambungan yang meliputi pengurangan dan penanganan sesuatu zat atau benda. Sampah adalah sisa dari kegiatan sehari-hari manusia atau proses alam yang berbentuk padat. Penelitian ini merupakan penelitian yang bertujuan untuk menghitung timbulan sampah dan merencanakan pengelolaan sampah dipasar pelita SK 17 yang direncanakan untuk 10 tahun mendatang. Populasi dalam penelitian ini adalah seluruh pedagang dan permukiman yang ada pada pasar pelita SK 17 Desa Bangun Karya, sedangkan sampelnya adalah pedangang dan masyarakat sekitar pasar. Timbulan sampah untuk lapak pedagang adalah 11, 875 liter/ lapak/hari, toko 2,578 ltr/org/hari, permukiman 0,969 ltr/org/hari. Volume sampah untuk proyeksi 2016-2026 lapak pedagang 926,25 ltr/hari, toko 959,016 ltr/hari, permukiman 2273,274 ltr/hari. Untuk perencanaan sampah Pasar Pelita SK 17 2017-2026 membutuhkan pewadahan organik berukuran 50 liter sebanyak 26 unit untuk lapak pedagang, 20 liter 93 unit untuk permukiman dan 31 unit untuk toko. Pewadahan sampah anorganik berjumlah 26 unit untuk lapak pedagang, 31 unit untuk pertokoan dan 93 unit untuk permukiman masing-masing berukuran 20 liter. Pewadahan sampah residu berukuran 20 liter untuk lapak pedagang berjumlah 26 unit, pertokoan 31 unit dan permukiman 93 unit. Sampah B3/B2 yang ditemukan hanya pada sumber sampah permukiman, untuk pewadahan sampah B3/B2 menggunakan pewadahan berukuran 20 liter berjumlah 93 unit.
\end{abstract}

Kata kunci : Pengelolaan Sampah; Pasar Pelita SK 17; Tanjung Jabung Timur.

\begin{abstract}
Management is a systematic, thorough and continuous activity which includes the reduction and handling of a substance or an object. Garbage is a remnant of human daily activities or natural processes shaped solid. This research is a research that aims to calculate waste generation and plan waste management in the SK17 lamp market planned for the next 10 years. The population in this study is all traders and settlements that exist in the market of Lamp SK 17 Bangun Karya Village, while the sample is the pedangang and the community around the market. Garbage generation for traders is 11, 875 liter / lapak / hari, shop 2,578 ltr / org / hari, settlement 0,969 ltr / org / hari. The volume of waste for 2016-2026 projected pedestrian street $926.25 \mathrm{ltr} /$ day, store 959,016 ltr / day, settlement 2273,274 ltr / day. For Pelita SK 2015-2026 waste market planning requires 50 liters of organic reserves of 26 units for traders, 20 liters 93 units for settlements and 31 units for shops. Inorganic garbage collection is 26 units for traders stalls, 31 units for shops and 93 units for settlements each measuring 20 liters. Wastewater residual waste measuring 20 liters for traders' shanties amounted to 26 units, shops 31 units and settlements 93 units. Garbage B3 / B2 found only in the source of waste settlements, for waste b3 waste / B2 using bins measuring 20 liters amounted to 93 units.
\end{abstract}

Keywords: Waste Management; SK 17 Pelita Market; East Tanjung Jabung.

\section{Pendahuluan}

Sampah merupakan sisa kegiatan sehari-hari manusia dan atau proses alam yang berbentuk padat (UU No 18 Tahun 2008). Sampah banyak ditemukan pada tempat-tempat umum yang menjadi masalah lingkungan masyarakat yang cukup mendesak. Karena tempat umum merupakan tempat bertemunya segala macam masyarakat dengan segala aktifitas yang dapat menimbulkan sampah. Dengan demikian maka tempat-tempat umum harus memenuhi syarat-syarat kesehatan dalam arti melindungi, memelihara, dan mempertinggi derajat kesehatan masyarakat (Mukono, 2006).

Pasar Pelita SK 17 terletak pada Desa Bangun Karya Kecamatan Rantau Rasau Kabupaten Tanjung Jabung Timur Provinsi Jambi dengan luas 1,9 ha (Google Earth Pro, 2015). Daerah pasar dan permukiman yang terletak di lahan basah yang terpengaruh oleh pasang surut mempunyai permasalahan pengelolaan sanitasi 
lingkungan. Salah satunya adalah pengelolaan sampah. Sampah hanya dibuang kesembarang tempat termasuk membuang ke sungai. Agar sampah tidak dibuang kesembarang tempat, maka perlu direncanakan sistem pengelolaan sampah pasar, baik lokasi maupun teknis pelaksanaanya.

\section{Metode Penelitian}

Lokasi perencanaan pengelolaan sampah adalah di Pasar Pelita SK 17 Desa Bangun Karya Kecamatan Rantau Rasau Kabupaten Tanjung Jabung Timur Provinsi Jambi, mencakup wilayah pasar, permukiman dan ruko di sekitar pasar.

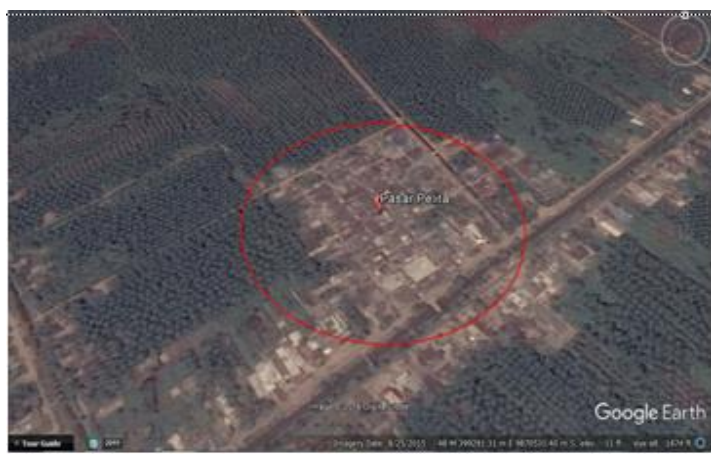

Gambar 1. Lokasi Titik Penelitian

Dalam penelitian ini yang menjadi populasi adalah seluruh pedagang dan permukiman yang ada pada Pasar Pelita SK 17 Desa Bangun Karya. Data jumlah seluruh populasi dapat dilihat pada tabel.

Tabel 1. Data Jumlah Seluruh Populasi

\begin{tabular}{ccc}
\hline No & Nama Populasi & Jumlah \\
\hline 1 & Lapak Pedagang & 60 \\
2 & Pertokoan & 75 \\
3 & Permukiman & 50 \\
& Jumlah & 185 \\
\end{tabular}

Sumber: Data Primer, 2016

a. Cara Pengambilan dan Pengukuran Timbulan Sampah

Adapun cara Pengambilan dan Pengukuran Sampel adalah sebagai berikut

a. Membagikan kantong plastik kepada masingmasing sumber sampah pada pagi hari jam 07.00 WIB;

b. Mengumpulkan kantong plastik yang telah dibagikan lalu diangkut ketempat pengukuran pada sore hari jam 17.00 WIB;

c. Memilah sampah sesuai dengan komposisi dan karakteristiknya, antara sampah organik, anorganik dan B2/B3; d. Menimbang berat sampah dan mengukur volume sampah;

Untuk mengukur volume sampah, masukkan sampah pada kotak pengukur lalu diangkat stinggi $20 \mathrm{~cm}$ lalu dihentakkan dan ulang sebanyak 3 kali, hingga sampah menjadi padat. Kemudian diukur ketinggian kotak yang telah dihentakkan, hasil perkalian panjang, lebar, dan tinggi sampah merupakan volume sampah yang didapat.

\section{b. Alat-alat Penelitian}

Adapun Peralatan dan Perlengkapan pada penelitian ini sebagai berikut :

a. Kantong plastik;

b. Sarung tangan, masker, sepatu, penggaris dan alatalat tulis;

c. Timbangan $0-100 \mathrm{~kg}$ dan $0-20 \mathrm{~kg}$;

d. Kotak pengukur volume $1,0 \mathrm{~m} \times 1,0 \mathrm{~m} \times 0,5 \mathrm{~m}$, dan kotak pengukur volume berukuran $20 \mathrm{~cm} \mathrm{x}$ $20 \mathrm{~cm} \times 20 \mathrm{~cm}$.

\subsection{Data Perencanaan}

1. Data primer

2. Data sekunder

a. Data primer terdiri dari :

1. Volume timbulan sampah;

2. Survey kondisi dan dokumentasi eksisting;

3. Hasil wawancara kepada pedagang.

b. Data sekunder terdiri dari :

1. Peta wilayah kecamatan;

2. Luas area pasar;

3. Jumlah lapak pedagang;

4. Jumlah toko;

5. Jumlah rumah;

6. Rona lingkungan sekitar pasar.

\section{Hasil dan Pembahasan}

Pada data pertambahan penduduk Desa Bangun Karya dari tahun 2007-2016 mengalami kenaikan dan penurunan yaitu pada tahun 2007 sampai 2008 mengalami kenaikan sebesar 2,088 \%, dan pada tahun 2009 sampai 2010 mengalami penurunan sebesar 7,2\%. 
Tabel 2. Proyeksi Pertambahan Penduduk

\begin{tabular}{|c|c|c|}
\hline No & Tahun & Jumlah Penduduk (Jiwa) \\
\hline 1 & 2017 & 2330 \\
\hline 2 & 2018 & 2332 \\
\hline 3 & 2019 & 2334 \\
\hline 4 & 2020 & 2335 \\
\hline 5 & 2021 & 2337 \\
\hline 6 & 2022 & 2339 \\
\hline 7 & 2023 & 2340 \\
\hline 8 & 2024 & 2342 \\
\hline 9 & 2025 & 2344 \\
\hline 10 & 2026 & 2346 \\
\hline
\end{tabular}

Tabel 3. Proyeksi Pertambahan Lapak Pedagang dan Toko

\begin{tabular}{|c|c|c|c|}
\hline No & Tahun & Pertambahan Lapak & Pertambahan Toko \\
\hline 1 & 2017 & 60 & 75 \\
\hline 2 & 2018 & 62 & 77 \\
\hline 3 & 2019 & 64 & 79 \\
\hline 4 & 2020 & 66 & 81 \\
\hline 5 & 2021 & 68 & 83 \\
\hline 6 & 2022 & 70 & 85 \\
\hline 7 & 2023 & 72 & 87 \\
\hline 8 & 2024 & 74 & 89 \\
\hline 9 & 2025 & 76 & 91 \\
\hline 10 & 2026 & 78 & 93 \\
\hline
\end{tabular}

\subsection{Hasil Survei Timbulan Sampah}

Hasil analisis timbulan sampah pertokoan diperoleh rata-rata volume timbulan sampah menurut jenisnya yaitu sampah organik dengan volume 0,00288 $\mathrm{m}^{3} /$ hari, sampah anorganik $0,00185 \mathrm{~m}^{3} /$ hari, sampah residu yang di timbulkan dari sumber sampah pertokoan
0,07975 $\mathrm{m}^{3} /$ hari. Timbulan sampah residu merupakan yang terbesar pada pertokoan dikarenakan jenis barang yang diperdagangkan pada pertokoan menggunakan kemasan kantong plastik yang merupakan sampah residu. Jumlah volume timbulan sampah pertokoan pada tahun 2017 sebesar $0,7734 \mathrm{~m}^{3} /$ hari.

Hasil analisis timbulan sampah lapak pedagang diperoleh rata-rata volume timbulan sampah menurut jenisnya yaitu sampah organik dengan volume 0,0877 $\mathrm{m}^{3} /$ hari, sampah anorganik $0,00075 \mathrm{~m}^{3} /$ hari, sampah residu yang di timbulkan dari sumber sampah lapak pedagang $0,00455 \mathrm{~m}^{3} /$ hari. Pada 8 hari pengukuran timbulan sampah lapak pedagang tidak ditemukan sampah B3 dan B2. Timbulan sampah organik merupakan yang terbesar pada lapak pedagang dikarenakan jenis barang yang diperdagangkan pada lapak pedagang merupakan sayura-sayuran. Jumlah volume timbulan sampah lapak pedagang pada tahun 2017 sebesar $0,7125 \mathrm{~m}^{3} /$ hari.

Hasil analisis timbulan sampah permukiman diperoleh rata-rata volume timbulan sampah menurut jenisnya yaitu sampah organik dengan volume 0,0123 $\mathrm{m}^{3} /$ hari, sampah anorganik $0,0067 \mathrm{~m}^{3} /$ hari, sampah B3/B2 0,000025 $\mathrm{m}^{3} /$ hari, sampah residu yang di timbulkan dari sumber sampah permukiman 0,01825 $\mathrm{m}^{3} /$ hari. Jumlah volume timbulan sampah permukiman pada tahun 2017 sebesar $0,24225 \mathrm{~m}^{3} /$ hari.

\subsection{Proyeksi Timbulan Sampah}

Hasil proyeksi timbulan sampah ditampilkanpada Tabel 4 sampai Tabel 9.

Tabel 4. Proyeksi Timbulan Sampah Permukiman

\begin{tabular}{|c|c|c|c|c|}
\hline \multirow{2}{*}{ No } & Tahun & $\begin{array}{c}\text { Penduduk } \\
\text { (Jiva) }\end{array}$ & \multicolumn{2}{|c|}{ Timbulan Sampah } \\
\cline { 4 - 5 } & & 2330 & 2,25777 & 824,08605 \\
\hline 1 & 2017 & 2332 & 2,259708 & 824,79342 \\
\hline 3 & 2018 & 2334 & 2,261646 & 825,50079 \\
\hline 4 & 2019 & 2335 & 2,262615 & 825,854475 \\
\hline 5 & 2021 & 2337 & 2,264553 & 826,561845 \\
\hline 6 & 2022 & 2339 & 2,266491 & 827,269215 \\
\hline 7 & 2023 & 2340 & 2,26746 & 827,6229 \\
\hline 8 & 2024 & 2342 & 2,269398 & 828,33027 \\
\hline 9 & 2025 & 2344 & 2,271336 & 829,03764 \\
\hline 10 & 2026 & 2346 & 2,273274 & 829,74501 \\
\hline
\end{tabular}


Tabel 5. Proyeksi Timbulan Sampah Toko

\begin{tabular}{|c|c|c|c|c|}
\hline \multirow{2}{*}{ No } & \multirow{2}{*}{ Tahun } & \multirow{2}{*}{ Jumlah Toko } & \multicolumn{2}{|c|}{ Timbulan Sampah } \\
\cline { 5 - 5 } & & & $\mathbf{M}^{3} /$ Hari & $\mathbf{M}^{3}$ Tahun \\
\hline 1 & 2017 & 75 & 0,7734 & 282,291 \\
\hline 2 & 2018 & 77 & 0,794024 & 289,81876 \\
\hline 3 & 2019 & 79 & 0,814648 & 297,34652 \\
\hline 4 & 2020 & 81 & 0,835272 & 304,87428 \\
\hline 5 & 2021 & 83 & 0,855896 & 312,40204 \\
\hline 6 & 2022 & 85 & 0,87652 & 319,9298 \\
\hline 7 & 2023 & 87 & 0,897144 & 327,45756 \\
\hline 8 & 2024 & 89 & 0,917768 & 334,98532 \\
\hline 9 & 2025 & 91 & 0,938392 & 342,51308 \\
\hline 10 & 2026 & 93 & 0,959016 & 350,04094 \\
\hline. & $\ldots-$ & $-\cdots-$ & & \\
\hline
\end{tabular}

Tabel 6. Proyeksi Timbulan Sampah Pedagang

\begin{tabular}{|c|c|c|c|c|}
\hline \multirow{2}{*}{ No } & Tahun & \multirow{2}{*}{$\begin{array}{l}\text { Jumlah } \\
\text { Lapak }\end{array}$} & \multicolumn{2}{|c|}{ Timbulan Sampah } \\
\cline { 4 - 5 } & & & $\mathbf{M}^{3} /$ Hari & $\mathbf{M}^{3} /$ Tahun \\
\hline 1 & 2017 & 60 & 0,7125 & 260,0625 \\
\hline 2 & 2018 & 62 & 0,73625 & 268,73125 \\
\hline 3 & 2019 & 64 & 0,76 & 277,4 \\
\hline 4 & 2020 & 66 & 0,78375 & 286,06875 \\
\hline 5 & 2021 & 68 & 0,8075 & 294,7375 \\
\hline 6 & 2022 & 70 & 0,83125 & 303,40625 \\
\hline 7 & 2023 & 72 & 0,855 & 312,075 \\
\hline 8 & 2024 & 74 & 0,87875 & 320,74375 \\
\hline 9 & 2025 & 76 & 0,9025 & 329,4125 \\
\hline 10 & 2026 & 78 & 0,92625 & 338,08125 \\
\hline
\end{tabular}

Tabel 7. Proyeksi Timbulan Perjenis Sampah Lapak Pedagang

\begin{tabular}{|c|c|c|c|c|c|}
\hline \multirow{2}{*}{ No } & \multirow{2}{*}{ Tahun } & Jumlah & \multicolumn{3}{|c|}{ Timbulan Sampah M M/Hari } \\
\cline { 4 - 6 } & & Lapak & Organik & Anorganik & Residu \\
\hline 1 & 2017 & 60 & 0,6576 & 0,005625 & 0,0342 \\
\hline 2 & 2018 & 62 & 0,67952 & 0,0058125 & 0,03534 \\
\hline 3 & 2019 & 64 & 0,70144 & 0,006 & 0,03648 \\
\hline 4 & 2020 & 66 & 0,72336 & 0,0061875 & 0,03762 \\
\hline 5 & 2021 & 68 & 0,74528 & 0,006375 & 0,03876 \\
\hline 6 & 2022 & 70 & 0,7672 & 0,0065625 & 0,0399 \\
\hline 7 & 2023 & 72 & 0,78912 & 0,00675 & 0,04104 \\
\hline 8 & 2024 & 74 & 0,81104 & 0,0069375 & 0,04218 \\
\hline 9 & 2025 & 76 & 0,83296 & 0,007125 & 0,04332 \\
\hline 10 & 2026 & 78 & 0,85488 & 0,0073125 & 0,04446 \\
\hline
\end{tabular}


Tabel 8. Proyeksi Timbulan Perjenis Sampah Toko

\begin{tabular}{|c|c|c|c|c|c|}
\hline \multirow{2}{*}{ No } & \multirow{2}{*}{ Tahun } & Jumlah & \multicolumn{3}{|c|}{ Timbulan Sampah $\mathbf{M}^{3} /$ Hari } \\
\cline { 4 - 6 } & & Toko & Organik & Anorganik & Residu \\
\hline 1 & 2017 & 75 & 0,027 & 0,01725 & 0,7476 \\
\hline 2 & 2018 & 77 & 0,02772 & 0,01771 & 0,767536 \\
\hline 3 & 2019 & 79 & 0,02844 & 0,01817 & 0,787472 \\
\hline 4 & 2020 & 81 & 0,02916 & 0,01863 & 0,807408 \\
\hline 5 & 2021 & 83 & 0,02988 & 0,01909 & 0,827344 \\
\hline 6 & 2022 & 85 & 0,0306 & 0,01955 & 0,84728 \\
\hline 7 & 2023 & 87 & 0,03132 & 0,02001 & 0,867216 \\
\hline 8 & 2024 & 89 & 0,03204 & 0,02047 & 0,887152 \\
\hline 9 & 2025 & 91 & 0,03276 & 0,02093 & 0,907088 \\
\hline 10 & 2026 & 93 & 0,03348 & $0,00,02139$ & 0,927024 \\
\hline
\end{tabular}

Gambar 11. Proyeksi Timbulan Perjenis Sampah Permukiman

\begin{tabular}{|c|c|c|c|c|c|c|}
\hline \multirow{2}{*}{ No } & \multirow{2}{*}{ Tahun } & \multirow{2}{*}{$\begin{array}{c}\text { Jumlah } \\
\text { (Jiwa) }\end{array}$} & \multicolumn{4}{|c|}{ Timbulan Sampah $\mathbf{M}^{3} /$ Hari } \\
\hline & & & Organik & Anorganik & B3/B2 & Residu \\
\hline 1 & 2017 & 2330 & 0,7223 & 1,9572 & 0,00145625 & 1,06248 \\
\hline 2 & 2018 & 2332 & 0,72292 & 1,95888 & 0,0014575 & 1,063392 \\
\hline 3 & 2019 & 2334 & 0,72354 & 1,96056 & 0,00145875 & 1,064304 \\
\hline 4 & 2020 & 2335 & 0,72385 & 1,9614 & 0,001459375 & 1,06476 \\
\hline 5 & 2021 & 2337 & 0,72447 & 1,96308 & 0,001460625 & 1,065672 \\
\hline 6 & 2022 & 2339 & 0,72509 & 1,96476 & 0,001461875 & 1,066584 \\
\hline 7 & 2023 & 2340 & 0,7254 & 1,9656 & 0,0014625 & 1,06704 \\
\hline 8 & 2024 & 2342 & 0,72602 & 1,96728 & 0,00146375 & 1,067952 \\
\hline 9 & 2025 & 2344 & 0,72664 & 1,96896 & 0,001465 & 1,068864 \\
\hline 10 & 2026 & 2346 & 0,72726 & 1,97064 & 0,00146625 & 1,069776 \\
\hline
\end{tabular}

Perencanaan pengelolaan sampah di Pasar Pelita SK 17 Kabupaten Jabung Timur Tahun 2017-2026 adalah: membutuhkan pewadahan sampah organik berukuran 50 liter sebanyak 26 unit untuk lapak pedagang, 20 liter 93 unit untuk permukiman dan 31 unit untuk toko. Pewadahan sampah anorganik berjumlah 26 unit untuk lapak pedagang, 31 unit untuk pertokoan dan 93 unit untuk permukiman masingmasing berukuran 20 liter. Pewadahan sampah residu berukuran 20 liter untuk lapak pedagang berjumlah 26 unit, pertokoan 31 unit dan permukiman 93 unit.

Sampah B3/B2 yang ditemukan hanya pada sumber sampah permukiman, untuk pewadahan sampah B3/B2 menggunakan pewadahan berukuran 20 liter berjumlah 93 unit. Pengangkutan menggunakan gerobak sampah berukuran $1 \mathrm{~m}^{3}$, gerobak sampah yang dibutuhkan sebanyak 2 unit gerobak dan 2 orang petugas kebersihan. TPS yang akan digunakan adalah TPS container yang berukuran $6 \mathrm{~m}^{3}$ sebanyak 1 unit. Pengomposan sampah organik permukiman menggunakan wadah dengan kapasitas 50 liter, wadah yang dibutuhkan sebanyak 93 unit, pengomposan sampah organik lapak pedagang dan toko menggunakan bangunan pengomposan.

\section{Kesimpulan}

Berdasarkan hasil analalisis, volume timbulan sampah untuk lapak pedagang 11,875 ltr/lapak/hari, toko 2,578 ltr/org/hari, permukiman 0,969 ltr/org/hari. Volume sampah untuk proyeksi 2016-2026 lapak pedagang 926,25 ltr/hari, toko 959,016 ltr/hari, permukiman 2273,274 ltr/hari. Dengan demikian diperlukan perencanaan pengelolaan sampah di Pasar Pelita SK 17 Kabupaten Janjung Jabung Timur untuk tahun 2017-2026 meliputi pewadahan, pengangkutan dengan geroba samph, penyediaan kontainer TPS dan metode pengomposan untuk sampah organik.

\section{Daftar Pustaka}

BPS. (2016) Rantau Rasau Dalam Angka, Kabupaten Tanjung Jabung Timur.

Damanhuri, Padmi. (2010). Komposisi Sampah Pasar.

Damsar. (2005). Sosiologi Pasar. Jakarta

Anonim. (1997). Sosiologi Ekonomi.

Mukono. (2006). Karakteristik Sampah Pasar. Jakarta

PP RI, (2012). Peraturan Pemerintah Republik Indonesia No 81 tentang Pengelolaan Sampah Rumah Tangga dan Sampah Sejenis Sampah Rumah Tangga. 
Perencanaan Pengelolaan Sampah Pasar Pelita SK 17 Desa Bangun Karya Kecamatan Rantau Rasau Kabupaten Tanjung Jabung

BSN. SNI 19-3964-1994 tentang Metode Pengambilan dan Pengukuran Contoh Timbulan dan Komposisi Sampah Perkotaan.

BSN. SNI 8152-2015 tentang Pasar Rakyat.

BSN. SNI 3242:2008 tentang Pengelolaan Sampah di Permukiman.

SSK. (2013). Setrategi Sanitasi Kota Kabupaten Tanjung Jabung Timur.

UU RI. (2008). Undang-undang Republik Indonesia No 18 tentang Pengelolaan Sampah.

UU RI. (1992). Undang-undang Republik Indonesia No 4 tentang Perumahan dan Permukiman. 